\title{
Reverse zoonotic tuberculosis transmission from an emerging Uganda I strain between pastoralists and cattle in South-Eastern Nigeria
}

Hezekiah Kehinde Adesokan ${ }^{{ }^{*}}$ (D), Victor Oluwatoyin Akinseye ${ }^{1}$, Elizabeth Maria Streicher ${ }^{2}$, Paul Van Helden², Rob Mark Warren ${ }^{2}$ and Simeon Idowu Cadmus ${ }^{1,3^{*}}$

\begin{abstract}
Background: Tuberculosis remains a major public health challenge globally with increasing risks for inter-transmission between pastoralists and cattle in Nigeria. This study was aimed at using molecular tools to establish zoonotic transmission of tuberculosis between pastoralists and their cattle in Ebonyi State, Nigeria. Sputum $(n=149)$ and milk $(n=144)$ samples from pastoralists and cattle, respectively were screened on the assumption of subclinical infections considering unguarded human-livestock interactions. Isolates obtained were analysed using deletion typing, spoligotyping and 24-Mycobacterial Interspersed Repetitive Unit-Variable Number Tandem Repeats (MIRU-VNTR).

Results: Fifty-four MTC were confirmed by deletion typing and were differentiated accordingly (M. tuberculosis: pastoralists $=42$, cattle $=2 ;$ M. bovis: pastoralists $=1$; M. africanum: pastoralists $=9$ ). Spoligotyping indicated $59.2 \%$ Uganda I/SIT46 (pastoralists =28; cattle = 1), 16.3\% Latin American Mediterranean/SIT61 (pastoralists =8), 2.0\% T/SIT53 (pastoralists $=1$ ) strains of $M$. tuberculosis and new strains of $M$. bovis and $M$. africanum. The 24-MIRU-VNTR of selected predominant cluster isolates shared by cattle and pastoralists (Uganda I/SIT46: pastoralists $=9$; cattle $=1$ ) showed the same number of copies at each of the repetitive loci.

Conclusions: Mycobacterium bovis was confirmed in humans and a reverse zoonotic tuberculosis transmission from an emerging Uganda I M. tuberculosis strain between pastoralists and cattle in Nigeria evidenced by MIRU-VNTR. Using molecular tools will help mitigate disease burden through informed epidemiological insights.
\end{abstract}

Keywords: Zoonoses, Molecular tools, Epidemiology, Mycobacterium tuberculosis complex, Public health

\section{Background}

Tuberculosis (TB) remains one of the most important threats to human and animal health. Currently, TB, particularly bovine tuberculosis (BTB) in humans also known as zoonotic TB is gaining awareness as a potentially important problem in developing countries, where no or only limited control measures are applied [1]. The United Nations Sustainable Development Goal 3 includes a target for ending the global TB epidemic and calls for diagnosis and treatment of every person with

\footnotetext{
*Correspondence: latterglory70@yahoo.co.in; simeonc5@gmail.com Simeon Idowu Cadmus is the senior corresponding author.

${ }^{1}$ Department of Veterinary Public Health and Preventive Medicine, University of Ibadan, Ibadan, Nigeria

Full list of author information is available at the end of the article
}

$\mathrm{TB}$ and that patients with zoonotic TB must be included. The intrinsic resistance of Mycobacterium bovis, the primary cause of BTB to pyrazinamide [2] and the fact that $M$. bovis patients are twice more likely to die during treatment [3] have made zoonotic TB in humans of great concern. The practice of humans and animals sharing the same micro-environment and dwelling premises has potentiated the disease [4]. Cough spray from infected cattle may be inhaled by occupationally exposed individuals resulting in typical pulmonary TB [5].

Within Africa, available evidence suggests that $M$. bovis causes approximately $2.8 \%$ of pulmonary TB cases, for a crude incidence of seven cases per 100,000 population [6]. In 2017, estimated incidence and mortality from

(c) The Author(s). 2019 Open Access This article is distributed under the terms of the Creative Commons Attribution 4.0 International License (http://creativecommons.org/licenses/by/4.0/), which permits unrestricted use, distribution, and 
M. bovis TB in Africa were 70,300 and 9270 , respectively [7], although this is likely to be a considerable underestimate, given the lack of definitive routine diagnostics used in most if not all African countries. Nigeria with an estimated population of over 190 million people is rated amongst the highest TB burden countries with a total case notification of 104,904 of which $78 \%$ were bacteriologically confirmed pulmonary in 2017 alone [7]. The high prevalence of zoonotic TB in humans clearly follows the high prevalence of TB in cattle [8]. However, TB can move in both directions and studies have indicated isolation of $M$. tuberculosis from cattle and $M$. bovis from humans [9-12].

In most developing countries including Nigeria, TB diagnosis is mostly based on smear microscopy and only limited cultural isolation despite risk factors for zoonotic transmission of Mycobacterium tuberculosis complex (MTC) species. This situation is further worsened by lack of or limited health care facilities in most rural settings where pastoralists reside. In developed countries, however, the use of molecular epidemiological techniques like deletion typing, spoligotyping and Mycobacteria Interspersed Repetitive Units-Variable Tandem Repeat (MIRU-VNTR) has contributed significantly to revealing on-going transmission of disease between animals and humans [13] by providing precise epidemiological insights required for optimal prevention and control measures. This study was aimed at using molecular tools to establish zoonotic TB transmission link between pastoralists and cattle in Ebonyi State which has a TB prevalence of $3.2 \%$ by smear microscopy [14] and where the pastoralists live with their cattle in the same micro-environment.

\section{Results}

\section{Culture and deletion analysis}

From a total of 149 pastoralists screened for TB, 54 (36.2\%) were positive for mycobacterial culture. Of these, deletion typing revealed $42(77.8 \%) M$. tuberculosis, one (1.9\%) M. bovis, nine (16.7\%) M. africanum and two (3.7\%) nontuberculous mycobacteria (NTM) (Table 1) giving a TB prevalence of $34.9 \%$. A total of 144 milk samples were obtained from 15 cattle herds in the state, out of which three animals $(2.1 \%)$ were positive for mycobacterial culture. The deletion typing identified two (66.7\%) of these as M. tuberculosis and the other (33.3\%) as NTM (Table 1) giving an overall TB prevalence of $1.4 \%$ in the cattle studied.

\section{Spoligotyping and MIRU-VNTR}

From the overall 54 MTC isolates obtained and subjected to spoligotyping (pastoralists $=52$, cattle $=2$ ), only 49 (pastoralists $=47$, cattle $=2$ ) showed clear and visible patterns. In all, 11 spoligotype patterns were obtained, resulting in an overall diversity (number of spoligotypes divided by the number of isolates, expressed as a percentage) of 22.5. A total of seven patterns occurred only once while four patterns were in clusters $(n=42)$ ranging from two to 29 isolates per cluster. Furthermore, classification based on family assignment revealed three previously known patterns including 59.2\% Uganda I [SIT46- pastoralists: 28, cattle: 1], 16.3\% Latin American Mediterranean- [SIT61, pastoralists: 8] and 2.0\% T- [SIT53 - pastoralists: 1] strains of $M$. tuberculosis. Eleven MTC isolates yielded eight new strains [pastoralists: 10, cattle: 1] comprising one new strain each of $M$. tuberculosis and M. bovis (one isolate each) and six of $M$. africanum (nine isolates) (Table 2).

Nine of the ten selected isolates (pastoralists: 9, cattle: 1) from the predominant Uganda I family cluster commonly shared between the pastoralists and one of their cattle from the same microenvironment demonstrated genetic relatedness by showing same number of copies at each repetitive unit, indicative of established reverse zoonotic transmission of TB between pastoralists and cattle in the state (Table 3). One isolate from the pastoralists failed to amplify.

\section{Discussion}

Available molecular epidemiological studies in Nigeria do not represent a confirmed picture of TB epi-links in the country despite the existing animal husbandry practices which enhance inter-transmission among humans and animals. Hence, TB control and informed prevention have been grossly limited. The present study reports a confirmed epi-link of reverse zoonotic TB transmission between pastoralists and cattle within the same microenvironment in Ebonyi State, Nigeria. To our knowledge, this is one of the first reports with confirmed TB inter-transmission amongst pastoralists and their cattle using 24 MIRU-VNTR in the country. Most previous reports on zoonotic transmission between humans and

Table 1 Distribution of Mycobacterium tuberculosis complex isolates according to sample types

\begin{tabular}{lcccccc}
\hline Sample type & No. screened & No. culture positive (\%) & \multicolumn{2}{l}{$\begin{array}{l}\text { Deletion typing } \\
\text { No. (\%) }\end{array}$} \\
\cline { 3 - 6 } & & & M. tuberculosis & M. bovis & M. africanum & NTM \\
\hline Milk & 144 & $3(2.1)$ & $2(66.7)$ & $0(0.0)$ & $0(0.0)$ & $1(33.3)$ \\
Sputum & 149 & $54(36.2)$ & $42(77.8)$ & $1(1.9)$ & $9(16.7)$ & $2(3.7)$ \\
\hline
\end{tabular}


Table 2 Spoligotype patterns of MTC isolates from pastoralists and cattle in Ebonyi, Nigeria

\begin{tabular}{|c|c|c|c|c|c|}
\hline Species/ spoligotype patterns & Number of isolates & No. in Cattle & No. in pastoralists & $\mathrm{SIT}^{*}$ & Family \\
\hline \multirow[t]{2}{*}{ M. bovis $(n=1)$} & 1 & 0 & 1 & & \\
\hline & 1 & 0 & 1 & NEW & Af1 \\
\hline \multirow[t]{5}{*}{ M. tuberculosis $(n=39)$} & 39 & 2 & 37 & & \\
\hline & 8 & 0 & 8 & 61 & LAM_CAM10 \\
\hline & 29 & 1 & 28 & 46 & Uganda I \\
\hline & 1 & 0 & 1 & 53 & T \\
\hline & 1 & 1 & 0 & NEW & Unique \\
\hline \multirow[t]{7}{*}{ M. africanum $(n=9)$} & 9 & 0 & 9 & & \\
\hline & 1 & 0 & 1 & NEW & Unique \\
\hline & 1 & 0 & 1 & NEW & Unique \\
\hline & 1 & 0 & 1 & NEW & Unique \\
\hline & 2 & 0 & 2 & NEW & Unique \\
\hline & 3 & 0 & 3 & NEW & Unique \\
\hline & 1 & 0 & 1 & NEW & Unique \\
\hline Total $(n=49)$ & 49 & 2 & 47 & & \\
\hline
\end{tabular}

*SIT: Spoligo International Type

cattle in Nigeria were based on the speciation of the Mycobacterium without molecular confirmation of the genetic relatedness of the strains $[15,16]$ or conclusions drawn from infected humans and animals from mutually exclusive populations [10]. Indirect data suggesting that humans suffering from active TB are the most probable source of $M$. tuberculosis in cattle have been described before [17]. However, we consider this present finding to be one of the first unequivocal reports of human-tocattle transmission of $M$. tuberculosis in Nigeria whereby we were able to confirm the genetic relatedness of the strain incriminated in the inter-transmission using molecular diagnostic techniques including 24 MIRU-VNTR.

Our findings showed that the reverse zoonotic transmission in the study area was due to an emerging Uganda I strain of $M$. tuberculosis from pastoralists to the infected cattle. The high prevalence of the Uganda I strain is an important epidemiological finding with significant implications for TB control. As observed, the Uganda I strain constituted $59.2 \%$ of the isolates recovered in the state. Generally, pastoralists are known for communal life-style, a critical factor that might promote human-to-human transmission of the strain [9]. Most of the pastoralists in the study area live within the same micro-environment and were known for congregational tendencies. These factors, coupled with poor practices (including unguarded close association between farmers and animals as well as consumption of unpasteurized milk) associated with this setting [9, 18] might further facilitate spread of infection from diseased to healthy individuals. Also, exacerbating risk factors such as HIV/ AIDS, drug addiction, alcoholism and smoking are prevalent among pastoralists in developing countries, including Nigeria. Unfortunately, most of these workers are unaware of their health status, leading to considerable delays in seeking health care $[9,18]$; thus promoting spread of infection from one person to the other. Besides, some modern strains are believed to exhibit more virulent phenotypes compared to ancient ones $[19,20]$, with emerging strains possessing inherent ability for adaptability and survival in the environment; thus circumventing routine treatment. This might further explain the reason for the high prevalence of this emerging strain.

The isolation of the two $M$. tuberculosis from milk samples in this study could not be as a result of contamination of milk by cough spray from infected humans. This is because the milk samples were collected from individual animals in an aseptic manner into sterile containers, showing the excretion of this organism from the cattle through milk. This is in line with previous reports of $M$. tuberculosis isolation in cow milk from several parts of the world [21-23]. As previously reported, humans are the initial source of $M$. tuberculosis infection for animals [22], with potential for this infection being carried back to humans. Vordermeier et al. [17] in a study in Ethiopia reported that though the extent and risk of infections caused by $M$. bovis are unclear, the facts that $M$. tuberculosis could be isolated from tuberculous cattle is a demonstration of a potential cattle-tohuman transmission risk. The impact of this disease can be devastating in poor or limited resource countries characterized with high burdens of both TB and HIV [24]. Therefore, control of TB due to M. tuberculosis in 
Table 3 Result of MIRU-VNTR typing of selected ten isolates from Uganda-I family cluster

\begin{tabular}{|c|c|c|c|c|c|c|c|c|c|c|}
\hline & \multicolumn{10}{|l|}{ Isolate ID* } \\
\hline & $\mathrm{C} 1$ & P1 & P 2 & P 3 & P 4 & P 5 & P 6 & P7 & P 8 & P 9 \\
\hline MIRU No. & \multicolumn{10}{|c|}{ No of repeats per locus } \\
\hline MIRU 2 & $2(508)^{* *}$ & 2 & 2 & 2 & 2 & 2 & 2 & 2 & 2 & Failed \\
\hline MIRU 4 & $2(276)$ & 2 & 2 & 2 & 2 & 2 & 2 & 2 & 2 & Failed \\
\hline MIRU 10 & $6(802)$ & 6 & 6 & 6 & 6 & 6 & 6 & 6 & 6 & Failed \\
\hline MIRU 16 & $4(777)$ & 4 & 4 & 4 & 4 & 4 & 4 & 4 & 4 & Failed \\
\hline MIRU 20 & $3(668)$ & 3 & 3 & 3 & 3 & 3 & 3 & 3 & 3 & Failed \\
\hline MIRU 23 & $7(518)$ & 7 & 7 & 7 & 7 & 7 & 7 & 7 & 7 & Failed \\
\hline MIRU 24 & $2(501)$ & 2 & 2 & 2 & 2 & 2 & 2 & 2 & 2 & Failed \\
\hline MIRU 26 & $5(540)$ & 5 & 5 & 5 & 5 & 5 & 5 & 5 & 5 & Failed \\
\hline MIRU 27 & $4(710)$ & 4 & 4 & 4 & 4 & 4 & 4 & 4 & 4 & Failed \\
\hline MIRU 31 & $4(704)$ & 4 & 4 & 4 & 4 & 4 & 4 & 4 & 4 & Failed \\
\hline MIRU 39 & $3(699)$ & 3 & 3 & 3 & 3 & 3 & 3 & 3 & 3 & Failed \\
\hline MIRU 40 & $4(570)$ & 4 & 4 & 4 & 4 & 4 & 4 & 4 & 4 & Failed \\
\hline Mtub 04 & $3(690)$ & 3 & 3 & 3 & 3 & 3 & 3 & 3 & 3 & Failed \\
\hline ETR-C & $3(324)$ & 3 & 3 & 3 & 3 & 3 & 3 & 3 & 3 & Failed \\
\hline Mtub 21 & $4(320)$ & 4 & 4 & 4 & 4 & 4 & 4 & 4 & 4 & Failed \\
\hline QUB-11b & $4(353)$ & 4 & 4 & 4 & 4 & 4 & 4 & 4 & 4 & Failed \\
\hline ETR-A & $3(420)$ & 3 & 3 & 3 & 3 & 3 & 3 & 3 & 3 & Failed \\
\hline Mtub 29 & $0(335)$ & 0 & 0 & 0 & 0 & 0 & 0 & 0 & 0 & Failed \\
\hline Mtub 30 & $3(421)$ & 3 & 3 & 3 & 3 & 3 & 3 & 3 & 3 & Failed \\
\hline ETR-B & $3(518)$ & 3 & 3 & 3 & 3 & 3 & 3 & 3 & 3 & Failed \\
\hline Mtub 34 & $4(542)$ & 4 & 4 & 4 & 4 & 4 & 4 & 4 & 4 & Failed \\
\hline Mtub 39 & $4(504)$ & 4 & 4 & 4 & 4 & 4 & 4 & 4 & 4 & Failed \\
\hline QUB 26 & $4(631)$ & 4 & 4 & 4 & 4 & 4 & 4 & 4 & 4 & Failed \\
\hline QUB4156 & $3(345)$ & 3 & 3 & 3 & 3 & 3 & 3 & 3 & 3 & Failed \\
\hline
\end{tabular}

${ }^{*} \mathrm{C}$ - Cattle; P - Pastoralist **Base pair corresponding to the number of repeats

humans does not depend only on the control of transmission among humans but also include breaking the transmission route particularly through bovine milk.

From this study, a new strain of $M$. bovis was detected in a pastoralist showing a possible zoonotic transmission from infected cattle. A previous study reported evidence of occupational exposure through the isolation of $M$. bovis from livestock workers in Ibadan, Nigeria [9]. Other studies have also confirmed $M$. bovis in humans including from Tanzania [25], Zaire and Egypt [5, 26]. In addition, the $M$. bovis isolates obtained in this study belonged to Af1 strains given their lack of spacer 30 which are known to be predominant in Cameroon, Nigeria and Mali [27].

The study also reported isolation of $M$. africanum from the pastoralists. This finding is in line with previous report that indicated that $M$. africanum strains are known as causative agents of human tuberculosis in
West Africa [28]. Besides, evidence of person to person transmission of $M$. africanum has also been reported [29], thus suggesting that an animal reservoir is not fully required.

This study, however, has some limitations. Firstly, the full clinical details of the infected pastoralists were not obtained. This could have given further credence to the findings observed from this study. Secondly, only cows were screened, whereas bulls could also harbour the infection. However, screening bulls would require tuberculin testing followed by slaughter and post-mortem of positive reactors. This would be problematic, since most farmers do not sell their animals except when in dire need of cash or the animals are unproductive.

\section{Conclusions}

The study provides a first report of a confirmed epi-link of reverse zoonotic TB transmission between pastoralists and cattle in Nigeria using molecular diagnostic techniques as 24-MIRU-VNTR. It established that the epilink was due to an emerging $M$. tuberculosis Uganda I strain circulating between pastoralists and cattle in Ebonyi State, Nigeria. We also report that the high proportions of this emerging strain has implications for $\mathrm{TB}$ epidemiology and control. Isolation of M. tuberculosis from cattle and $M$. bovis from the pastoralist further reiterates the zoonotic nature of TB. Hence, clinical laboratories should routinely use molecular tests to identify mycobacterial species and differentiate $M$. bovis from M. tuberculosis. Finally, it shows that detection of zoonoses with the aim of informed disease control in animals and humans could be enhanced through molecular-guided cooperation between human and veterinary health services.

\section{Methods}

\section{Study site and setting}

This cross-sectional study carried out in Ebonyi State, south-eastern Nigeria was a step further to our initial study which focused on determining genetic diversity of Mycobacterium tuberculosis complex strains in livestock workers and cattle in Nigeria [15]. The present study was aimed at using molecular tools including 24 MIRUVNTR to establish zoonotic TB transmission link between pastoralists and cattle in the state. The majority of pastoralists in the state known for communal life-styles, live in farm settlements within the same vicinity with regular opportunities for convergence through social gatherings and cultural rites. This thus creates an environment conducive for intra- and inter-transmission of TB from infected to non-infected cattle and humans. 


\section{Sample size and sample collection Human sampling}

Cattle farm settlements were identified through the Ministry of Agriculture and Natural Resources in the state. Following visits paid to the traditional head of the settlements, a meeting was convened with all potential participants where the objectives and benefits of the study were explained to them. Oral consents were thereafter obtained from those willing to participate given the low educational status of most of the pastoralists. Based on $7.1 \%$ prevalence of $M$. bovis infection among livestock workers in Nigeria [30], an estimated minimum sample size of 101 participants was obtained following the procedure for sample size estimation [31]. However, a total of randomly selected 149 pastoralists participated in the study including their wives, children who were at least 18 years old as well as their cattle handlers. Sputum samples were consecutively collected early in the morning over a period of six months using sterile, plastic sample containers from one of every four household members who consented to participate in the study until the sample size was reached. They were guided to void the sputum samples in open air and not in confined or overcrowded places in order to avoid generating infective aerosols. Identification code was written on each sputum container and all collected samples were placed in an ice-packed cool flask.

\section{Animal sampling}

All lactating cows from the herds of the consenting participants were selected, from which $10 \mathrm{~mL}$ of milk was aseptically collected into a $20 \mathrm{~mL}$ sterile sample container through the assistance of the livestock owners. The udders of the individual cows were cleaned and disinfected before the collection of the sample in order to avoid contamination of the milk sample. The collected samples were appropriately labelled and kept in a cool flask containing ice-packs. Data on the size of the herds was documented.

All samples collected from the pastoralists and their cattle were transported in the respective cool transport flasks to the Tuberculosis Laboratory of the Department of Veterinary Public Health and Preventive Medicine, University of Ibadan, where they were refrigerated prior to processing. Each batch of samples were processed within one-week post-collection.

\section{Sample processing}

Milk sample processing was done on separate days apart from sputum samples to eliminate risk of crosscontamination. Samples were processed following a described procedure using Mycoprep decontaminant [32]. The concentrates thus obtained each from sputum and milk samples were inoculated onto two slopes of
Löwenstein-Jensen with either glycerol or pyruvate and incubated at $37^{\circ} \mathrm{C}$ for 12 weeks. Positive growths were harvested and subjected to deletion typing to identify $M$. tuberculosis complex isolates by the polymerase chain reaction (PCR) amplification of genomic regions of difference (RD), as described elsewhere [33]. Isolates identified as members of MTC were thereafter processed by spoligotyping as earlier reported [15] following a standardized international method previously described [34] using a commercially available kit (Isogen Biosciences BV, Maarsen, The Netherlands). Briefly, $25 \mu \mathrm{l}$ of amplified PCR product was diluted in $160 \mu \mathrm{l}$ of $2 \mathrm{X}$ SSPE- $-1 \%$ SDS and denatured by heat at $72{ }^{\circ} \mathrm{C}$ for $10 \mathrm{mins}$. The diluted samples were immediately placed on ice and then $150 \mu \mathrm{l}$ of each diluted sample was pipetted into respective parallel channel of the membrane in such a way that the channels of the miniblotter apparatus were perpendicular to the rows of oligonucleotides on the membrane. Hybridization was done for 60 mins at $60{ }^{\circ} \mathrm{C}$ without allowing shaking of the miniblotter to avoid cross contamination of samples. After hybridization, the samples were removed from the membrane using aspirator. The membrane was then washed twice in $250 \mathrm{ml}$ of 2X SSPE/0.5\% SDS for $10 \mathrm{~min}$ each time at $60^{\circ} \mathrm{C}$ and then incubated in diluted streptavidin-peroxidase conjugate (Boehringer) and 2X SSPE/0.5\% SDS at 1:4000 for $60 \mathrm{~min}$ at $42^{\circ} \mathrm{C}$. The membrane was washed twice, for $10 \mathrm{~min}$ each time, in $250 \mathrm{ml}$ of $2 \mathrm{X} \mathrm{SSPE} / 0.5 \% \mathrm{SDS}$ at $42{ }^{\circ} \mathrm{C}$ and rinsed with $250 \mathrm{ml}$ of $2 \mathrm{X}$ SSPE for $5 \mathrm{~min}$ at room temperature. Detection of hybridizing DNA was done by incubating the membrane in $20 \mathrm{~mL}$ chemiluminescent ECL (Amersham) detection liquid for $1.5 \mathrm{mins}$, followed by exposure to X-ray film (Hyperfilm ECL; Amersham) for $20 \mathrm{~min}$ in accordance with the instructions of the manufacturer. Mycobacterium tuberculosis H37Rv, M. bovis Bacille Calmette-Guérin and sterile distilled water were used as controls. Resulting spoligotype patterns were compared to existing patterns in an international spoligotyping database (SITVIT2) [35] available at http://www.pasteur-guadeloupe.fr:8081/ SITVITDemo/. Spoligotype patterns were grouped as spoligotype international types (SITs) if they shared identical spoligotype patterns with patterns present in the existing database. Spoligotype families were assigned as previously described [35]. Of these spoligotype families identified and earlier published [15], selected isolates from the predominant cluster commonly shared between pastoralists and cattle belonging to the same microenvironment were genotyped by PCR amplification of 24 MIRU-VNTR as earlier described [36] using primers that amplify 24 polymorphic loci on the mycobacterial genome per DNA isolate. Briefly, $2 \mu \mathrm{l}$ of mycobacterial DNA was added to a final volume of $25 \mu \mathrm{l}$ containing $8.375 \mu \mathrm{l}$ of free RNase water (Qiagen, USA), 
$5 \mu \mathrm{l}$ of $\mathrm{Q}$ solution, $2.5 \mu \mathrm{l}$ of $10 x$ buffer, $2 \mu \mathrm{l}$ of $1.5 \mathrm{mM}$ $\mathrm{MgCl}_{2}$ (Roche, USA), $4 \mu \mathrm{l}$ of $0.2 \mathrm{mM}$ dNTPs (Promega, WI USA), $1 \mu \mathrm{l}$ primer and $0.125 \mu \mathrm{l}$ of HotStar Taq polymerase $(1 \mathrm{U})$. The PCR conditions included three stages: initial denaturation at $95^{\circ} \mathrm{C}$ for $15 \mathrm{~min}$ (Stage 1), second denaturation at $94{ }^{\circ} \mathrm{C}$ for $1 \mathrm{~min}$, annealing at $62^{\circ} \mathrm{C}$ for 1 min, initial extension for $1 \mathrm{~min}$ at $72^{\circ} \mathrm{C}$ (Stage 2) and final extension at $72{ }^{\circ} \mathrm{C}$ for $10 \mathrm{~min}$ followed by cooling to $4{ }^{\circ} \mathrm{C}$ prior to analysis (Stage 3). A 45 -cycles PCR was done on Veriti $^{\text {Tu }}$ 96-well Thermal Cycler (Applied Bio system, Singapore). The laboratory $M$. tuberculosis H37Rv reference strain DNA was used as positive control and DNA-free water as a negative control. Amplification products were electrophoretically fractionated in $1 \%$ agarose gel $\left(\mathrm{SeaKem}^{\circ} \mathrm{LE}\right)$ in $1 x \mathrm{TE}$ buffer at $160 \mathrm{~V}$ for $4 \mathrm{~h}$ to allow maximum fragment size separation for clear discrimination. The number of tandem repeat units present at each locus was calculated from the size of DNA fragments according to a standardized table (http://www.MIRU-VNTRplus.org). The results were expressed in digital format where each number represented the number of repeat copies at a particular locus. The isolates from the pastoralists were those from cattle handlers belonging to the same herd with the cattle positive for the shared cluster.

\section{Abbreviations \\ ACUREC: Animal care, use and research ethics committee; BTB: Bovine tuberculosis; DNA: Deoxyribonucleic acid; ECL: Electrochemiluminescence; HIV/AIDS: Human infectious virus/acquired immunodeficiency syndrome; MIRU-VNTR: Mycobacterial Interspersed Repetitive Unit-Variable Number Tan- dem Repeats; MTC: Mycobacterium tuberculosis complex; \\ NTM: Nontuberculous mycobacteria; PCR: Polymerase chain reaction; RD: Regions of difference; SDS: Sodium dodecyl sulfate; SIT: Spoligo international type; SSPE: Saline-sodium phosphate EDTA; TB: Tuberculosis}

\section{Acknowledgements}

We appreciate the kind assistance of Dr. Ephraim Nwanga, Mr. and Dr. (Mrs) Otuh and the members of staff of the Ministry of Agriculture and Natural Resources, Ebonyi State.

\section{Authors' contributions}

HKA and SIC developed the concept of the study, collected the samples and all required data; HKA, VOA, PH, RMW and EMS processed the samples, analyzed and interpreted the data, and drafted the manuscript. All authors read and approved the final manuscript.

\section{Funding}

The study was supported in part, by a grant from the Tertiary Education Trust Fund (TETFund) of Federal Republic of Nigeria under the Academic Staff Training and Development Scheme of the University of Ibadan, Nigeria. The funding body did not play any role in the design of the study and collection, analysis, and interpretation of data and in writing the manuscript.

\section{Availability of data and materials}

The datasets used and/or analysed during the current study are available from the corresponding author on reasonable request.

\section{Ethics approval and consent to participate}

Ethical approvals for the study were obtained from the University of Ibadan/ University College Hospital Ethics Committee with approval number: NHREC/ 05/01/2008a and the University of Ibadan Animal Care, Use and Research Ethics Committee, with approval number: UI-ACUREC/App/2015/072. Oral consent was obtained from each participant since many of them could not read or write. The Confidentiality of the participants was maintained by using codes on the sputum cups. Oral consents obtained were documented in the research notebook against the respective codes. Using oral consents in such settings as this is in line with the institutional ethics committees of the University which approved the protocols. Participants who were confirmed to have TB were connected to the Directly Observed Therapy Short-Course centres close to them for treatment and follow-up. The pastoralists with infected herds were advised to present their herds to the Veterinary Department of the state for tuberculin screening.

\section{Consent for publication \\ Not Applicable.}

\section{Competing interests}

The authors declare that they have no competing interests.

\section{Author details}

${ }^{1}$ Department of Veterinary Public Health and Preventive Medicine, University of Ibadan, Ibadan, Nigeria. ${ }^{2}$ DST-NRF Centre of Excellence for Biomedical Tuberculosis Research/SAMRC Centre for Tuberculosis Research, Division of Molecular Biology and Human Genetics, Faculty of Medicine and Health Sciences, Stellenbosch University, Tygerberg, South Africa. ${ }^{3}$ Center for Control and Prevention of Zoonoses, University of Ibadan, Ibadan, Nigeria.

Received: 4 April 2019 Accepted: 22 November 2019

Published online: 04 December 2019

\section{References}

1. World Health Organization (WHO), Food and Agriculture Organization of the United Nations (FAO), World Organisation for Animal Health (OIE), International Union Against Tuberculosis and Lung Disease (IUATLD). Road map for zoonotic tuberculosis, 2017. 48th union world conference on lung health; Guadalajara: Mexico; 2017

2. de Jong BC, Onipede A, Pym AS, Gagneux S, Aga RS, DeRiemer K, et al. Does resistance to pyrazinamide accurately indicate the presence of Mycobacterium bovis? J Clin Microbiol. 2005:43(7):3530-2.

3. Rodwell TC, Moore M, Moser KS, Brodine SK, Strathdee SA. Tuberculosis from Mycobacterium bovis in binational communities, United States. Emerg Infect Dis. 2008;14(6):909-16.

4. Shitaye JE, Tsegaye W, Pavlik I. Bovine tuberculosis infection in animal and human populations in Ethiopia: a review. Vet Med. 2007;52(8):317-32.

5. Cosivi O, Grange JM, Daborn CJ, Raviglione MC, Fujikura T, Cousins DV, et al. Zoonotic tuberculosis due to Mycobacterium bovis in developing countries. Emerg Infect Dis. 1998;4(1):59-70.

6. Müller B, Durr S, Alonso S, Hattendorf J, Laisse CJ, Parsons SD. Zoonotic Mycobacterium bovis-induced tuberculosis in humans. Emerg Infect Dis. 2013;19:899-908.

7. World Health Organisation. Global tuberculosis report, 2018, WHO/CDS/TB/ 2018.20, Geneva: Switzerland: WHO, 2018.

8. Asiak IE, Ohore OG, Emikpe BO, Abatan OO, Ockiya MA. The use of ELISA in the detection of bovine tuberculosis in slaughtered cattle and sedentary herds in South Western Nigeria. J Anim Vet Adv. 2007;7:883-6.

9. Adesokan HK, Jenkins AO, van Soolingen D, Cadmus SIB. Mycobacterium bovis infections in livestock workers in Ibadan, Nigeria: evidence of occupational exposure. Int J Tuberc Lung Dis. 2012;16(10):1388-1392(5).

10. Jenkins AO, Cadmus SI, Venter EH, Pourcel C, Hauk Y. Molecular epidemiology of human and animal tuberculosis in Ibadan, southwestern Nigeria. Vet Microbiol. 2011;151:139-47.

11. Cadmus S, Palmer S, Okker M, Dale J, Gover K, Smith N, et al. Molecular analysis of human and bovine tubercle bacilli from a local setting in Nigeria. J Clin Microbiol. 2006;44:29-34.

12. Ocepek M, Pate M, Zolnir-Dovc M, Poljak M. Transmission of Mycobacterium tuberculosis from human to cattle. J Clin Microbiol. 2005:43:3555-7.

13. Figueiredoa ES, Ramos DF, Medeiros L, Silvestre FG, Lilenbaum W, Silva JT, et al. Multiple strains of Mycobacterium bovis revealed by molecular typing in a herd of cattle Eduardo. Vet J. 2012;193:296-8.

14. Oshi DC, Omeje JC, Oshi SN, Alobu IN, Chukwu NE, Nwokocha C, et al. An evaluation of innovative community-based approaches and systematic tuberculosis screening to improve tuberculosis case detection in Ebonyi state, Nigeria. Int J Mycobacteriol. 2017;6:246-52. 
15. Adesokan HK, Streicher EM, van Helden PD, Warren RM, Cadmus SIB. Genetic diversity of Mycobacterium tuberculosis complex strains isolated from livestock workers and cattle in Nigeria. PLoS One. 2019;14(2): e0211637.

16. Ibrahim S, Cadmus SIB, Umoh JU, Ajogi I, Farouk UM, Abubakar UB, et al. Tuberculosis in humans and cattle in Jigawa State, Nigeria: risk factors analysis. Vet Med Int 2012; Article ID 865924, 5 pages.

17. Vordermeier M, Ameni G, Berg F. The influence of cattle breeds on susceptibility to bovine tuberculosis in Ethiopia. Comp Immunol Microbiol Infect Dis. 2012;35:227-32.

18. Adesokan HK, Akinseye VO, Sulaimon MA. Knowledge and practices about zoonotic tuberculosis prevention and associated determinants amongst livestock workers in Nigeria; 2015. PLoS One. 2018;13(6): e0198810.

19. Coll F, McNerney R, Guerra-Assuncao JA, Glynn JR, Perdigao J, Viveiros M, et al. A robust SNP barcode for typing Mycobacterium tuberculosis complex strains. Nat Commun. 2014:5:4812.

20. Reiling N, Homolka S, Walter K, Brandenburg J, Niwinski L, Ernst M, et al. Clade-specific virulence patterns of Mycobacterium tuberculosis complex strains in human primary macrophages and aerogenically infected mice. mBio. 2013;4(4):e00250-13.

21. Bezerra AV, Dos Reis EM, Rodrigues RO, Cenci A, Cerva C, Mayer FQ. Detection of Mycobacterium tuberculosis and Mycobacterium avium Complexes by real-time PCR in bovine milk from Brazilian dairy farms. J Food Prot. 2015;78(5):1037-42.

22. BhanuRekha V, Gunaseelan L, Pawar G, Nassiri R, Bharathy S. Molecular detection of Mycobacterium tuberculosis from bovine milk samples. J Adv Vet Anim Res. 2015;2(1):80-3.

23. Srivastava K, Chauhan DS, Gupta P, Singh HB, Sharma VD, Yadav VS, et al. Isolation of Mycobacterium bovis and M. tuberculosis from cattle of some farms in North India--possible relevance in human health. Indian J Med Res. 2008;128(1):26-31.

24. Parsons LM, Somoskövi A, Gutierrez C. Laboratory diagnosis of tuberculosis in resource poor countries: challenges and opportunities. Clin Microbiol Rev. 2011;24:314-50.

25. Mfinanga SG, Morkve O, Kazwala RR, Cleaveland S, Sharp MJ, Kunda J, et al. Mycobacterial adenitis: role of Mycobacterium bovis, non-tuberculous mycobacteria, HIV infection, and risk factors in Arusha, Tanzania. East Afr Med J. 2004;81(4):171-8.

26. Nafeh MA, Medhat A, Abdul-Hameed AG, Ahmad YA, Rashwan NM, Strickland GT. Tuberculous peritonitis in Egypt: the value of laparoscopy in diagnosis. Am J Trop Med Hyg. 1992;47:470-7.

27. Muller B, Hilty M, Berg S, Garcia-Pelayo MC, Dale J, Boschiroli ML, et al. African 1, an epidemiologically important clonal complex of Mycobacterium bovis dominant in Mali, Nigeria, Cameroon, and Chad. J Bacteriol. 2009;191:1951-60.

28. Yeboah-Manu D, de Jong BC, Gehre F. The biology and epidemiology of Mycobacterium africanum. Adv Exp Med Biol. 2017;1019:117-33.

29. Winglee K, Manson McGuire A, Maiga M, Abeel T, Shea T, Desjardins CA, et al. Whole genome sequencing of Mycobacterium africanum strains from Mali provides insights into the mechanisms of geographic restriction. PLoS Negl Trop Dis. 2016;10:e0004332.

30. Adesokan HK. Bacteriological screening of livestock workers at Bodija municipal abattoir and Akinyele cattle market, Ibadan for tuberculosis. Thesis, Master of Veterinary Public Health, University of Ibadan, Ibadan, 2008.

31. Thrusfield M. Determinants of disease. 3rd ed. Hoboken: Black Well publishing; 2005

32. Becton Dickinson. Becton Dickinson BBL ${ }^{\text {TM }}$ Mycoprep ${ }^{\text {TM }}$ Specimen digestion/ decontamination kit manual for processing of mycobacterial specimens 1999; 2.

33. Warren RM, Gey van Pittius NC, Barnard M, Hesseling A, Engelke E, De Kock $M$, et al. Differentiation of Mycobacterium tuberculosis complex by PCR amplification of genomic regions of difference. Int J Tuberc Lung Dis. 2006; 10:818-22.

34. Kamerbeek J, Schouls L, Kolk A, van Agterveld M, van Soolingen D, Kuijper $\mathrm{S}$, et al. Simultaneous detection and strain differentiation of Mycobacterium tuberculosis for diagnosis and epidemiology. J Clin Microbiol. 1997;35(4): 907-14

35. Brudey K, Driscoll JR, Rigouts L, Prodinger WM, Gori A, Al-Hajoj SA, et al. Mycobacterium tuberculosis complex genetic diversity: mining the fourth international spoligotyping database (SpolDB4) for classification, population genetics and epidemiology. BMC Microbiol. 2006;6:23.
36. Supply P, Allix C, Lesjean S, Cardoso-Oelemann M, Rusch-Gerdes S, Willery E. Proposal for standardization of optimized mycobacterial interspersed repetitive unit-variable- number tandem repeat typing of Mycobacterium tuberculosis. J Clin Microbiol. 2006;44:4498-510.

\section{Publisher's Note}

Springer Nature remains neutral with regard to jurisdictional claims in published maps and institutional affiliations.
Ready to submit your research? Choose BMC and benefit from:

- fast, convenient online submission

- thorough peer review by experienced researchers in your field

- rapid publication on acceptance

- support for research data, including large and complex data types

- gold Open Access which fosters wider collaboration and increased citations

- maximum visibility for your research: over $100 \mathrm{M}$ website views per year

At BMC, research is always in progress.

Learn more biomedcentral.com/submissions 